\title{
FATORES RELACIONADOS À INCIDÊNCIA E DISSEMINAÇÃO DO VÍRUS DO MOSAICO COMUM DO MILHO*
}

\author{
ANA CARLA L. ALMEIDA ${ }^{1 * *}$, ELIZABETH OLIVEIRA $^{2} \&$ RENATO O. RESENDE ${ }^{3}$ \\ ${ }^{1}$ Departamento de Fitopatologia, Universidade de Brasília, CEP 70910-900, Brasília-DF; ${ }^{2}$ Empresa Brasileira de \\ Pesquisa Agropecuária, Centro Nacional de Pesquisa de Milho e Sorgo, Cx. Postal 151, CEP 35701-970, \\ Sete Lagoas, MG; ${ }^{3}$ Laboratório de Microscopia Eletrônica, Departamento de Biologia Celular, \\ Universidade de Brasília, CEP 70910-900, Brasília-DF, e-mail: rresende@unb.br.
}

(Aceito para publicação em 09/05/2001)

Autor para correspondência: Renato O. Resende

ALMEIDA, A.C.L., OLIVEIRA, E. \& RESENDE, R.O. Fatores relacionados à incidência e disseminação do vírus do mosaico comum do milho. Fitopatologia Brasileira 26:766-769. 2001.

\section{RESUMO}

O mosaico comum do milho (Zea mays) destaca-se, atualmente, entre as doenças mais importantes dessa cultura, sendo causada por um complexo de potyvirus transmitido por afídeos. Esse trabalho teve por objetivo a identificação de fatores que podem contribuir para a incidência dessa virose e disseminação do seu agente causal. Plântulas de 115 cultivares dos Ensaios Nacionais de Milho-Centro foram submetidas a quatro inoculações com o complexo viral, utilizando-se, em cada uma, parcelas com cinco plantas de cada cultivar. A maioria das cultivares mostrou-se suscetível, apresentando sintomas da virose, aos 15 dias após a inoculação. Espécies de gramíneas também foram inoculadas e mostraram-se hospedeiras desses vírus. Através do teste
dot-ELISA, a presença dos vírus do mosaico comum foi detectada em folhas de milho provenientes de vários municípios dos estados de São Paulo, Minas Gerais e Goiás. No período de mar/97 a fev/98, dois híbridos de milho foram plantados mensalmente, e semanalmente avaliados quanto à incidência do mosaico comum. Observou-se tendência de maior incidência nos plantios de novembro, dezembro e janeiro, coincidindo com as elevadas temperaturas e precipitações pluviométricas do verão. Os resultados obtidos contribuem para a recomendação de medidas para o controle dessa virose.

Palavras-chave adicionais: Potyvirus, Zea mays, Potyviridae.

\section{ABSTRACT \\ Factors related to incidence and dissemination of Maize common mosaic virus}

In recent years, mosaic became one of the most important diseases affecting maize (Zea mays) crops. It is caused by a potyvirus complex transmitted by aphid species. The aim of this work was to identify factors that may contribute to increase the incidence and dissemination of this disease. Seedlings of 115 cultivars from three different National Maize Cultivars Trials were tested for their susceptibility to the virus complex via mechanical inoculation of five plants of each cultivar, between October/97 and February/98. Most cultivars were susceptible and showed mosaic symptoms 15 days after inoculation. Several graminaceous species were also inoculated and showed to be hosts of the potyvirus complex. Using the dot-ELISA test, the virus complex could be detected in maize plants collected from different regions of São Paulo, Minas Gerais and Goias states. Between March/97 and February/98 two maize inbred lines were planted monthly and incidence of mosaic was evaluated weekly. The highest incidence was observed in the summer, coinciding with the increase of temperature and the levels of rainfall. These results may contribute to recommending control measures.
O mosaico comum do milho (Zea mays L.) foi relatado pela primeira vez no Brasil em 1971 como sendo causado

*Parte da Tese de Mestrado do primeiro autor. Universidade de Brasília. (1998)

**Bolsista da CAPES por estirpes do vírus do mosaico da cana-de-açúcar (Sugarcane mosaic virus - SCMV) família Potyvirudae, gênero Potyvirus (Costa et al., 1971) e durante vários anos foi considerado de importância econômica limitada para essa cultura (Balmer, 1980). Recentemente, essa virose tem se destacado entre as doenças mais importantes na cultura do 
Fatores relacionados à incidência e disseminação do vírus do mosaico comum...

milho, devido ao aumento em sua incidência e às perdas que pode causar na produção (Waquil et al., 1996; Dudienas et al., 1997; Oliveira et al., 1997). A virose é causada por um complexo de vírus do gênero Potyvirus (Almeida,1998), transmitidos na natureza por várias espécies de afídeos, distinguindo-se o pulgão do milho, Rhopalosiphum maidis L., pela eficiência na transmissão (Edwardson \& Christie, 1991). A existência de um elevado número de estirpes desses potyvirus que causam o mosaico comum do milho e que podem sobreviver em outras espécies hospedeiras pertencentes à família Poaceae (Edwardson \& Christie, 1991), aumenta a importância da doença. Entre as medidas recomendadas para controle do mosaico comum do milho destacam-se a utilização de cultivares resistentes e a eliminação de fontes de inóculo, proporcionadas pela presença de gramíneas infetadas na área de plantio do milho (Shurtleff, 1986; Fernandes \& Oliveira ,1997). O conhecimento dos fatores que podem interferir na ocorrência e disseminação dos vírus responsáveis por essa virose são aspectos importantes a serem considerados quando se pretende a adoção de medidas para seu controle ou o estabelecimento de programas de pesquisa para esse fim. Esse trabalho teve por objetivo avaliar a suscetibilidade de cultivares de milho e de espécies de gramíneas cultivadas e selvagens (plantas daninhas) em relação ao mosaico comum; avaliar a influência da época de plantio sobre sua incidência em milho e verificar sua distribuição geográfica em regiões produtoras desse cereal.

Cultivares experimentais e comerciais de milho incluídas nos Ensaios Nacionais de Milho-Região Centro, do ano agrícola de 1997/98, foram avaliados com relação à suscetibilidade ao mosaico comum do milho, causado por potyvirus. Foram utilizados nessa avaliação: o Ensaio Nacional de Milho Normal (ENM Normal), com 36 cultivares; o Ensaio Nacional de Milho superprecoce (ENM Superprecoce), com 30 cultivares e o Ensaio Nacional de Milho Precoce (ENM Precoce), com 49 cultivares.

As 115 cultivares foram semeadas em canteiros de alvenaria, contendo solo e esterco de curral como substrato e, uma semana após a germinação foram submetidas à inoculação com os vírus responsáveis pelo mosaico comum. A inoculação foi feita pela fricção do inóculo em uma folha de cada plântula, após pulverização com carborudum 600 mesh e em seguida, essas foram lavadas com água. O inóculo foi preparado pela maceração de folhas de milho, com sintomas de mosaico comum, em tampão fosfato $0,01 \mathrm{M}, \mathrm{pH}$ 7,4 , em proporção 1:5 (peso/volume). O complexo viral foi obtido a partir de amostras de folhas de milho coletadas na área experimental da EMBRAPA Milho e Sorgo, Sete Lagoas (MG), e mantido em plantas de milho cultivar Br-01, em casa de vegetação. As cultivares dos ensaios nacionais foram submetidas a quatro inoculações, utilizando-se em cada uma, parcelas com cinco plantas de cada cultivar. As inoculações foram realizadas no período de outubro de 1997 a fevereiro de 1998. Aos 15 dias após cada inoculação, foram feitas avaliações observando-se a presença ou ausência de sintomas de mosaico nas plantas. Considerando-se as quatro inoculações, determinou-se para cada cultivar, o percentual de plantas que apresentou sintomas da virose.

Quatorze espécies gramíneas da família Poaceae, sendo quatro espécies cultivadas e nove espécies selvagens, que se incluem entre as plantas daninhas mais comuns em lavouras de milho, foram avaliadas quanto à suscetibilidade ao mosaico comum do milho. As espécies cultivadas foram: aveia (Avena sativa L.), cana-de-açúcar (Saccharum officinarum L.), sorgo granífero (Sorghum bicolor L.), trigo [Triticum aestivum (L.) Thell.], milho e as espécies selvagens foram: brizanta [Brachiaria brizantha (Hochstetter) Stapf], braquiária (B. decumbens Stapf), capim-marmelada [B. plantaginea (Link) Hitch.], braquiária (B. ruziziensis Stapf), capim-carrapicho (Cenchrus echinatus L.), capim-colchão (Digitaria horizontalis Willd.), capim-pé-de-galinha [Eleusine indica (L.) Gaertner], milheto [Pennisetum americanum (L.) Leeke], capim-massambará [S. halepense (L.) Pers.].

Sementes dessas espécies gramíneas, com exceção da cana-de-açúcar que foi propagada vegetativamente (tolete), foram germinadas em vasos, em casa de vegetação e as plântulas obtidas, em estádio de duas a três folhas foram submetidas à inoculação com os vírus do mosaico comum do milho. O inóculo foi obtido de folhas de milho apresentando sintomas dessa virose e foi preparado e inoculado como descrito anteriormente. $\mathrm{O}$ experimento foi repetido em duas ocasiões distintas. Em cada uma determinou-se o número de plantas apresentando sintomas da virose, dez a 15 dias após a inoculação. A presença de potyvirus nessas plantas foi confirmada através do teste sorológico dot-ELISA, utilizandose IgG para o complexo viral e metodologia descritas por Almeida et al. (2000).

Durante dois anos, duas cultivares de milho foram mensalmente plantadas e avaliadas semanalmente, até a época do florescimento, com relação à incidência do mosaico comum. Cada cultivar foi plantada em uma única parcela constituída por quatro fileiras de $5 \mathrm{~m}$, com espaçamento de $0,5 \mathrm{~m}$ entre linhas e $0,25 \mathrm{~m}$ entre plantas. Foram realizadas adubações de acordo com resultados da análise de fertilidade do solo e recomendação de adubação para o milho. $\mathrm{O}$ experimento foi conduzido na área experimental da Embrapa Milho e Sorgo, em Sete Lagoas (MG). Durante a condução do experimento foram registradas, diariamente, as temperaturas máxima e mínima, na estação de climatologia da Embrapa Milho e Sorgo. Ao final das avaliações determinouse o percentual de plantas apresentando sintomas da virose, para cada cultivar.

Amostras de folhas de milho apresentando sintomas de mosaico, provenientes de diversos municípios, localizados em regiões produtoras de milho, nos Estados de São Paulo, Goiás e Minas Gerais, foram analisadas através de teste sorológico, para verificar a presença de potyvirus. Para deteç̧ão dos potyvirus, as amostras foram submetidas ao teste sorológico dot-ELISA, utilizando-se IgG e metodologia descritas por Almeida et al. (1999). As amostras foram coletadas em lavouras de milho localizadas nos municípios de Jardinópolis (SP); Guaíra (SP); Votuporanga (SP) Assis 
(SP); Colômbia (SP); Santa Helena de Goiás (GO), Vargem Bonita (DF), Planaltina (DF); Uberlândia (MG); Unaí (MG); Pirapora (MG); Sete Lagoas (MG). Essas amostras foram obtidas através de solicitações feitas a pesquisadores de outras Instituições e a técnicos de empresas produtoras de sementes de milho.

A inoculação do complexo viral do mosaico comum nas cultivares de milho constituintes dos Ensaios Nacionais de Milho-Região Centro, evidenciou que a maioria é suscetível a esse vírus (Figura 1). Cerca de 50\% do total de cultivares avaliadas apresentou incidência de sintomas superior a $50 \%$. Apenas uma cultivar, dentre as 115 , mostrou-se altamente resistente ao vírus, não apresentando sintomas de mosaico, nas quatro inoculações realizadas.

Dentre as 36 cultivares do ENM Normal, apenas quatro apresentaram incidência de sintomas de mosaico inferior a $20 \%$; oito apresentaram incidência entre 21 e $50 \%$ e 22 cultivares apresentaram incidência superior a $50 \%$ (Figura 1A). Com relação ao ENM Superprecoce, oito cultivares apresentaram incidência inferior a $20 \%$; nove apresentaram valores entre 21 a $50 \%$ e 13 apresentaram incidência superior a 50\% (Figura 1B). Dentre as 49 cultivares do ENM Precoce, quatro cultivares apresentaram menos de $20 \%$ das plantas com sintomas de mosaico; 15 apresentaram incidência entre 21 e $50 \%$ e 29 cultivares apresentaram incidência superior a 50\% (Figura 1C). Entre essas cultivares do ENM Precoce, apenas uma não apresentou sintomas de mosaico, nas quatro inoculações realizadas. Esses resultados mostram que a suscetibilidade ao complexo viral, assim como a expressão de seus sintomas, aparentemente, não é influenciada pelo ciclo fenológico da cultivar.

Dentre as 14 espécies gramíneas testadas, oito mostraram-se susceptíveis, apresentando sintomas típicos de mosaico (Tabela 1). Os sintomas, em geral, iniciaram-se 10 a 15 dias após a inoculação e desenvolveram-se de acordo com a descrição característica para a virose. As espécies que não mostraram sintomas foliares característicos foram: aveia, $B$. brizantha, $B$. ruziziensis, cana-de-açúcar, capim-massambará e trigo. Sorgo-Rio mostrou ser a espécie mais suscetível, sendo que algumas plantas apresentaram necroses nas folhas. As plantas com sintomas evidentes de mosaico tiveram a infecção confirmada através do resultado positivo do dot-ELISA. No caso de plantas assintomáticas, pôde-se constatar através desse teste sorológico, que algumas plantas de capimcarrapicho e de milheto, mesmo não mostrando sintomas da doença, estavam infetadas pelos vírus.

Além do milho e do sorgo, as espécies selvagens capimmarmelada, capim-colchão e capim-pé-de-galinha destacaram-se pela alta susceptibilidade, apresentando maiores percentuais de plantas com sintomas de mosaico e maior severidade desses sintomas.

Os resultados da avaliação de incidência do mosaico comum, em função da época de plantio do milho e as médias de precipitação pluviométrica, de temperatura e de umidade relativa, registradas durante o período de avaliação, mostraram uma tendência de maior incidência nos plantios de
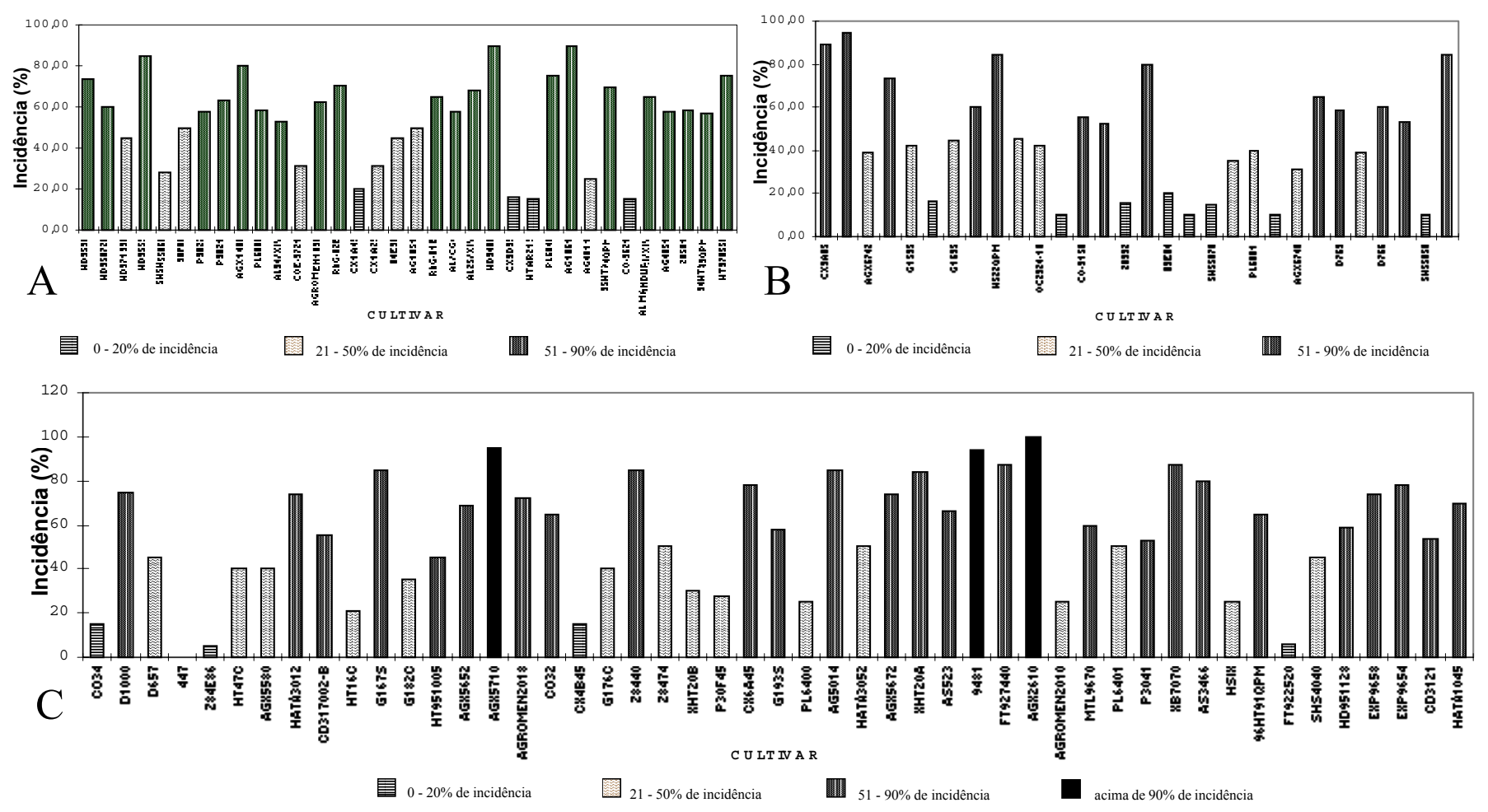

FIG. 1 - Incidência de sintomas de mosaico em cultivares do Ensaio Nacional de Milho (ENM) - Região Centro, inoculados com os vírus do mosaico comum do milho (Maize dwarf mosaic virus, MDMV). A) ENM Normal; B) ENM Superprecoce; C) ENM Precoce. 
Fatores relacionados à incidência e disseminação do vírus do mosaico comum...

TABELA 1 - Suscetibilidade de espécies gramíneas cultivadas e selvagens ao complexo viral do mosaico comum do milho

\begin{tabular}{|c|c|c|c|}
\hline Espécie gramínea & $\begin{array}{c}1^{\text {a }} \text { avaliaçãa }{ }^{*} \\
(\%)\end{array}$ & $\begin{array}{c}2^{\mathrm{a}} \text { avaliação* } \\
(\%)\end{array}$ & $\begin{array}{c}\text { Reação } \\
\text { Sintomatológica** }\end{array}$ \\
\hline Avena sativa & $0 / 18(0)$ & - & SS \\
\hline Brachiaria brizantha & - & $0 / 30(0)$ & SS \\
\hline B. decumbens & $17 / 24(71)$ & $6 / 14(43)$ & ML \\
\hline B. plantaginea & $14 / 14(100)$ & - & MS \\
\hline B. ruziziensis & - & $0 / 30(0)$ & SS \\
\hline Cenchrus echinatus & $4 / 24(16)$ & $2 / 9(22)$ & ML \\
\hline Digitaria horizontalis & $15 / 15(100)$ & $18 / 30(60)$ & MM, MS \\
\hline Eleusine indica & $14 / 14(100)$ & $7 / 11(64)$ & MM, MS \\
\hline Pennisetum americanum & $8 / 18(44)$ & $2 / 14(14)$ & ML, MM \\
\hline Saccharum officinarum & $0 / 10(0)$ & - & SS \\
\hline Sorghum bicolor & $15 / 15(100)$ & $12 / 12(100)$ & MS \\
\hline S. halepense & $0 / 15(0)$ & $0 / 30(0)$ & SS \\
\hline Triticum aestivum & - & $0 / 30(0)$ & SS \\
\hline Zea mays L. & $15 / 15(100)$ & - & MS \\
\hline \multicolumn{4}{|c|}{$\begin{array}{l}\text { * número de plantas com sintomas / número de plantas inoculadas } \\
\text { ** SS - planta sem sintoma; ML - mosaico leve; MM - mosaico moderado; MS } \\
\text { - mosaico severo } \\
\text { - plantas não testadas }\end{array}$} \\
\hline
\end{tabular}

novembro, dezembro e janeiro, coincidindo com precipitações pluviométricas e temperaturas mais elevadas do verão, condições provavelmente favoráveis ao desenvolvimento dos afídeos vetores.

Através do teste dot-ELISA, a presença dos potyvirus foi confirmada nas amostras de folha de milho apresentando sintomas típicos de mosaico, provenientes dos municípios de São Paulo (Vale do Paranapanema e Alta Mogiana), Minas Gerais, Goiás e Distrito Federal. Observa-se assim, que a virose encontra-se disseminada em importantes regiões produtoras de milho.

Constata-se também a existência de variabilidade genética com relação à resistência aos vírus do mosaico comum, confirmando-se resultados obtidos por Waquil et al. (1996), que observaram a suscetibilidade de vários híbridos comerciais de milho à infecção pelos vírus e também a existência de fontes de resistência.

Importante ressaltar que tem sido demonstrado que a herança da resistência ao Maize dwarf mosaic virus (MDMV) e SCMV é do tipo monogênica e dominante, podendo ser incorporada a cultivares comerciais. Entretanto, deve-se considerar também a grande variabilidade dos vírus componentes do complexo viral do mosaico comum, o que sugere a necessidade de mais estudos com relação à distribuição e predominância desses potyvirus, visando ao desenvolvimento de cultivares resistentes, além de pesquisas adicionais incluindo experimentos de transmissão envolvendo o vetor.

A utilização de cultivares suscetíveis, as alterações em épocas de plantio, com a realização freqüente de plantios tardios, nos meses de novembro, dezembro e janeiro; o provável acúmulo de inóculo, proporcionado pela presença de plantas daninhas hospedeiras e a presença de inóculo disse- minado nas regiões produtoras, são fatores que podem explicar a ocorrência de surtos e aumentos na incidência da virose.

Por outro lado, o conhecimento desses fatores permitem também a recomendação de medidas de controle para essa virose, incluindo a eliminação de fontes de inóculo proporcionadas pela presença de plantas daninhas gramíneas apresentando sintomas de mosaico, possivelmente presentes nas áreas destinadas ao plantio de milho e adequação da época de plantio para o mês de outubro.

\section{REFERÊNCIAS BIBLIOGRÁFICAS}

ALMEIDA, A.C.L., OLIVEIRA, E. \& RESENDE, R.O. Detecção de vírus por RT-PCR, hibridização "Dot-blot" e "Dot-ELISA em milho com mosaico comum. Fitopatologia Brasileira 25:168-174. 2000.

ALMEIDA, A.C.L. Detecção, caracterização e aspectos epidemiológicos do complexo viral do mosaico comum do milho (Zea mays L.). (Tese de Mestrado). Brasília. Universidade de Brasília. 1998.

BALMER, E. Doenças do milho. In: Galli, F. (Ed.) Manual de Fitopatologia. São Paulo.Editora Agronômica Ceres. 1980. pp. 371-391.

COSTA, A.S., KITAJIMA, E.W. \& ARRUDA S.C. Moléstias de vírus e de micoplasma do milho em São Paulo. Fitopatologia Brasileira 4:39-41. 1971.

DUDIENAS, C., DUARTE, A.P., PATERNIANI, M.E.A.G.Z., RIBEIRO, J.L.,BIANCHINI, M.T., KANTHACH, R.A.D., CASTRO, J.L., SILVEIRA, L.C.P., DENUCCI, S., JUNIOR, J. S., BOLONHESI, D. \& DE SORDI, G. Severidade de doenças no milho "safrinha" no Estado de São Paulo em 1996. In: Seminário sobre a cultura do milho "safrinha", 4., IAC/ CDV. 1997. pp.107-115.

EDWARDSON, J.R. \& CHRISTIE, R.G. The potyvirus group. Volumes 1-4, Florida Agricultural Experiment Station, Monograph 16, 1991.

FERNANDES, F.T. \& OLIVEIRA, E. Principais doenças na cultura do milho. EMBRAPA-CNPMS, Sete Lagoas MG. Circular Técnica, n.26. 1997.

OLIVEIRA, E., WAQUIL, J.M. \& PINTO, N.F.J.A. Doenças causadas por patógenos transmitidos por insetos: complexo enfezamento/mosaico. In: Seminário sobre a cultura do milho "safrinha", 4, IAC/CDV.1997. pp. 8794

SHURTLEFF, M.C. Compendium of corn diseases. $2^{\text {nd }}$ ed. Saint Paul. American Phytopathological Society. 1986.

WAQUIL, J.M., OLIVEIRA, E., PINTO, N.F.J.A., FERNANDES, F.T. \& CORREIA, L.A. Viroses em milho, incidência e efeito na produção. Fitopatologia Brasileira 21:460-463. 1996. 